\title{
Practices and politics of collaborative urban infrastructuring: Traffic Light Box Artworks in Dublin Streets
}

\author{
Sung-Yueh Perng, Social Sciences Institute, Maynooth University, Ireland \\ sung-yueh.perng@mu.ie \\ The Programmable City \\ The Programmable City Working Paper 33 \\ http://progcity.maynoothuniversity.ie/

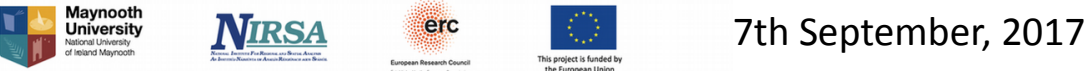

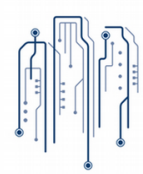

\begin{abstract}
Cities are transformed into sites of experimentation through large-scale smart city initiatives, but the visions and practices of establishing public, private and civic partnerships are often overshadowed by corporate interests, governance convenience and efficiency, with an overemphasis on technological innovations. Instead of relying on these partnerships, civic hacking initiatives seek to develop collaboration between programmers and community members, on the one hand, and government officials and organisations, on the other, for experimenting prototyping processes that foreground community needs. These initiatives are considered as pursuing open, inclusive and collaborative governance and is analysed through the lens of collaborative urban infrastructuring to attend to the dynamics, consequences and implications emerging from the prototyping processes. The analysis of the collaboration between Code for Ireland and Dublin City Council Beta suggests that the spatio-temporal scaling of prototypes lead to the continual and contested scaling of skills, knowledges, capabilities, organisational procedures and socio-technical arrangements. These heterogeneous scaling engenders desirable futures and future problems. The articulation and enactment of the values that attract diverse visions, viewpoints and practices into collaborative experimentation can be challenged by agonistic relationships arising from exploring practical arrangements for the mutual shaping of desirable governance procedures and the organisational expectations, obligations and constraints that are already in place. Furthermore, in the processes of scaling, there are constant dangers of enacting patriarchal stewardships and taking an all-knowing position for caring and evaluating impacts, which makes it critical to also experiment with ways of disclosing urban techno-politics that emerges continuously and in unanticipated ways.
\end{abstract}

\section{Keywords:}

Civic hacking; smart cities; citizen engagement; social innovation; infrastructure; governance; 


\section{Introduction}

Cities are transformed into sites of urban experimentation as public, private and civic initiatives incorporate digital and data-driven technologies to improve urban governance and everyday life. Dublin, New York and Boston are some of the pioneering cities that are, or will soon to be, equipped with networks of sensors to develop smart districts, innovation centres and, ultimately, 'quantified communities' that run on 'new physical and informatics technologies and analytics capabilities' (CUSP, 2014). At the same time, local governments establish partnerships with civic hacking organisations, such as Code for America and its local and global brigades, to 'build open source technology and organize a network of people dedicated to making government services simple, effective, and easy to use'.$^{1}$ In such collaboration, diverse organisations, people, values, viewpoints, expertise and skills are enrolled in the hopes for taking part in the making of future cities and trialling collaborative ways of assembling technologies, governments and the public.

However, in this changing landscape of engineering digital urbanism, the hopes and practices associated with these initiatives raise critical questions concerning the dynamics, consequences and implications of pursuing civic urban experimentation. Similar to many smart city initiatives, the development plan of these initiatives celebrates new horizons of citizen engagement and participation, but also creates serious problems where only passive, instrumental and obedient forms of civic actions are permitted (Mattern, 2016). Also, civic hacking incorporates the sensitivity and culture towards transparency and openness from early free and open source software (F/OSS) but its long-term approach to the collaboration with the government does not necessarily translate into change in organisational structure or culture within the government for taking collective responsibility with the public (Perng and Kitchin, 2016). Furthermore, many partnerships between local governments and multinational corporations result in cities being 'assembled piecemeal, integrated awkwardly into existing configurations of urban governance and the built environment' (Shelton et al., 2015: 15). These partnerships can be further affected by 'messy processes of implementation that are often resisted by units and staff who are used to existing systems and procedures and have limited resources to help effect change management' (Kitchin et al., 2016: 99).

This paper adds to the analysis of urban techno-politics by examining public experimentation for more open, inclusive and collaborative governance. It investigates collaborative making of technology and future cities and demonstrates how urban techno-politics emerges from negotiating

1 Quoted from Code for America website, https://www.codeforamerica.org/ [Accessed 13 May 2015]. 
visions, values and practical arrangements during experimentation. In such urban experimentation, a government does not stay as a coherent entity that includes or excludes particular values or partnerships with civic hacking organisations. Instead, by articulating and enacting wider societal values associated with the experimentation in practical ways, a government is reshaped by the explorations of establishing alliances, adjustments and arrangements involving certain parts of a government with the hopes and accompanying challenges of affecting others. The empirical examination in the paper draws on a case study on the collaboration between a section of Dublin City Council (DCC) and a civic hacking organisation, Code for Ireland, to regenerate Dublin’s street-scape. The data were collected through ethnographic engagement and observation on civic hacking and the project conducted in Dublin between 2014 and 2015, and the interview with the coordinator of the collaboration between Code for Ireland and DCC.

\section{Citizens, participation and digital technology}

The analysis of the paper develops from the increasing literature on material participation and politics that unpacks how heterogeneous sets of 'tools', from paper and policy documents to arts and technological prototypes, constitute or contest in the processes of making parliaments, politics and futures (Asdal and Hobæk, 2016; Barry, 2013; Gabrys and Yusoff, 2012; Law and Singleton, 2014). Further articulating concerns that arise in the context of collaborating with the public to reshape the city, I also drawn on participatory approaches to design, especially on information infrastructure, to pay particular attention towards how material and technological arrangements of prototypes, trials or workshops can cause concerns to the social and ethical potentials that these collaborative experiments set out to achieve (Björgvinsson et al., 2010; Karasti and Baker, 2008; Liegl et al., 2016). These approaches are combined in the paper to destabilise the government as the centre of knowledge, expertise and technology, and also to disassemble 'the government' for analysing the relocation of innovation into the context of urban everyday life and the promises and politics that occur during the process.

\section{Changing relationships between government and technology}

\section{Destabilising government and technology}

The relationships between urban governance, citizens and technology have never been stable. As Dawes (2009) demonstrates, a wide range of ideals and practices have been developed as modern societies adopt technology to improve the functioning of the government. For Weber (1964), an 
ideal form of governance relies on technical specialisation and the legitimacy of exercising technical and governmental authority to deal with complex societal issues. This form of governance in turn produces its own problems of overspecialisation, routinisation and path dependency where problem-defining and -solving become predefined and highly embedded in institutional and economic rationality, allowing little room for revision and change (Berkhout, 2002). Subsequent social and technological developments, particularly information and communication technologies (ICTs), played a significant part in the transformation of societies, particularly cities, into services and knowledge production whereby societies become governed by global networks of information, technological elites and flexible capitalism (Bell, 1973; Castells, 1996).

This transformation has consequential impacts on how the government in an information age should be devised and implemented and how civic actions could be pursued. There have been varied attempts to connect the government with ICT developments. However, these mostly take utilitarian approaches, focusing on management issues around development or procurement strategies, increases of work efficiency and effectiveness through ICT infrastructure designs, improvements on internal information sharing and interoperability (Coleman, 2008; Dawes, 2009). Other conceptions of the government and the citizen also suggest changing relationships between the two. These ICT developments can be conceived as creating digital platforms for government as 'service provider', and the receiving end more as 'customers' or 'clients' than 'citizens'. These conceptualisations mark a transition towards understanding government as an enterprise or an authoritative provider for people in subordinate conditions, and less as setting up a channel for deliberative democracy through digital engagement (Dutil et al., 2008).

\section{Civic hacking and urban governance}

At the same time, global and local initiatives are pursued to leverage digital civic media and collaborative making of technology for reshaping the public sphere and urban governance. Networked media and information technologies, as Castells (2008) argues, are crucial to new, ad hoc and global alliances that foster public debates and civic actions on social and political issues. Furthermore, civic hacking is another bottom-up attempt to challenge the established ways of conducting urban governance. Civic hacking draws inspirations from the liberal sensitivity established by F/OSS (Coleman, 2013) and also builds on the momentum of open data and open knowledge movements for enhancing government transparency and accountability through widening access to information held by the government. Resisting to become 'proto-publics' that 
are contingently and temporarily formed by and highly dependent on individual civic hackathons (Lodato and DiSalvo, 2016), civic hacking organisations also seek ‘a longer-term’ approach and partnership with sympathetic staff or units within the government to form 'recursive publics' (Kelty, 2008) that seek to establish scalable, modular, open and transparent ways of using technology for addressing community issues (Maalsen and Perng, 2016).

However, various concerns are also raised for rethinking the social, governmental and political economic consequences of these initiatives. For example, the 'value' of releasing government data is also often considered in terms of commercial re-use of the data and thus the governmental generation, archival and release of data become mechanisms of deregulation and neoliberalisation of urban governance (Bates, 2012). The long-term effects, extents of change and the decline of government responsibility are also concerns for the incorporation of civic hacking, or hackathons, as an added model for local governments to address community problems (Janssen et al., 2012; Johnson and Robinson, 2014).

\section{Opening up government through infrastructuring}

Collaboration with local or national governments is already challenging considering that they are often fragmented entities with mutually conflicting interests and visions (Kitchin et al., 2016). Furthermore, government agencies can uphold disparate practices, procedures and experiences towards civic collaboration and the extent to which they can scale their organisations, skills and expertise in the process can add further complexities to the pursuits of alternative urban governance. I further draw on the notion of infrastructuring, particularly in the context of participatory design (Björgvinsson et al., 2010), to analyse 'collaborative urban infrastructuring' and the politics emerging from experimenting new ways of city and infrastructure making. This re-orientation of research emphases builds on the problematisation of the privileged institutions, including governments and research and industrial hubs, in design and innovation and the relocation of sites of innovation and experimentation into everyday life contexts and practices (Liegl et al., 2016; Suchman, 2011).

\section{Processes of collaborative urban infrastructuring}

The processes of collaborative urban infrastructuring are continual and situated, as well as dynamic and contested. Conducting public urban experiments for infrastructure making requires time for the collaboration to establish alliances, develop trust and deploy prototypes and trials. The collaboration 
therefore requires continual attempts and situated socio-technical arrangements for enabling and deploying trials and prototypes (Karasti et al., 2010). However, building desirable future cities by the collaboration of governmental and civic hacking organisations inevitably brings in incompatible voices, visions and actions that contest one another. The collaboration between differently motivated organisations and individuals can lead to unexpected consequences and socio-technical relationships arising from the deployment. Accordingly, the collaboration also forms 'agonistic public spaces’ for democratising innovation (Bjögvinsson et al., 2012; Björgvinsson et al., 2010; Le Dantec and DiSalvo, 2013).

In the process of forming civic and government collaboration, however, the agonistic spaces and relationships do not necessarily rest upon the opposition between 'the government' and 'the people'. Rather, competing alliances can build on incompatible views and practices where social, technological and institutional arrangements in support of these views and practices assemble differently motivated initiatives, individuals and governmental units and agencies to participate (Barry, 2013; Karasti, 2014). Accordingly, examinations on civic and governmental collaboration for technology making have to remain sensitive to 'socio-material assembly that deals with "matters of concern” ... and the alignment of controversies, ready for unexpected use, opening up new ways of thinking and behaving’ (Björgvinsson et al., 2010: 41-3).

\section{Temporal and spatial scaling}

Temporal and spatial scaling is another important issue in collaborative urban infrastructuring. By undertaking a longer-term approach and aiming for spatially scalable solutions, civic hacking share similar interests with design projects that adopt participatory approaches and seek spatial and temporal expansion of trials to enhance their inclusiveness (Karasti et al., 2010). The concerns of temporal and spatial scaling derive from reconsidering the where and when of uses, users and the purposes and consequences of building information infrastructure (Star and Ruhleder, 1996). Star and Ruhleder's approach is further expanded to problematise where and when design takes place and question the people, knowledge, practices and viewpoints that are inscribed into or unwillingly precluded from technology designs and innovations (Björgvinsson et al., 2010; Suchman, 2011).

In civic hacking, decisions about what technologies to use, where to test the prototype and the length of each round of tests carry equal weight as design methods, particularly ethnographically informed ones, in making ‘spaces of possibilities' for prototypes, civic hacking practices and their 
collaborations with supporting government agencies. These spaces of prototyping are continuously 'carved out' by the civic and governmental collaboration, through its 'selecting, connecting, and bounding the site' and engaging with 'material artifacts and the people who define the field' (Blomberg and Karasti, 2013: 389). The temporal and spatial scaling to select, relate and reconfigure the places, time, people, organisations and knowledge are thus ways of 'prototyping in situ' to produce 'grounded imagination' (Büscher et al., 2004). This way of prototyping and grounding imagination can also be useful for civic hacking initiatives and collaborating government units to conduct continual and practical trials for not only reflecting upon the experiences but also disclosing unanticipated practices, consequences and challenges in relation to wider societal and ethical values.

\section{Values, pragmatic arrangements and agonistic relationships}

Furthermore, the values attached to individual trials or to collaborative urban infrastructuring cannot be treated as stable or having predefined qualities. Instead, they are entangled in the pragmatic arrangements and agonistic relationships emerging from urban experiments. The spatiotemporal scaling of the experiments aims to be inclusive of diverse societal and ethical viewpoints and practices. The relocation of sites of design, innovation and experimentation into urban environments provide materials means for wider participation in prototyping futures (Gabrys and Yusoff, 2012; Marres, 2012). But the scaling also develops complex and sometimes contradictory practices that complicate the social and organisational arrangements aimed at supporting these values. As exemplified by the various open movements above, values associated with governmental and civic collaborations open up potentials for a more transparent government. These collaborations, however, also lead to attempts of neoliberalising urban governance through setting up technological and commercial means for capitalising on data that belong to the public.

Accordingly, the societal and ethical values of democratising access to the experiments have to be considered as 'the product of engagement with the technology, by directly or indirectly implicated publics' and 'subject to processes of change and negotiations' (Liegl et al., 2016: 87-92). In the context where agonistic relationships develop as the experiments scale spatially and temporally, the values perceived at the outset of a trial can become contested and uncertain, which has knock-on effects on whether the futures and visions as initially promised are still attainable in social, ethical and pragmatic terms. Accordingly, it is crucial to examine the enactment of values rather than the frames that stabilise them by attending to the different articulations of values, as well as their 
relationships with city futures, the spatio-temporal arrangements for articulating these values and the socio-technical configurations allowing them to materialise.

\section{Towards collaborative urban infrastructuring}

Drawing upon the discussion so far, several key aspects are outlined below for analysing how a government can be destabilised, dissembled and reassembled to form new socio-technical arrangements to pursue collaborative urban infrastructuring:

- specifying government staff or agencies, and their motivations, skills, expertise and knowledge, for devising practical arrangements to align government organisations and procedures with civic hacking initiatives;

- attending to the changing cultures and practices as they respond to initiatives of collaborative making of data and technologies; and

- articulating the politics arising from the difficulty of aligning and adjusting practical arrangement for pursuing wider societal and ethical values that collaborative urban infrastructuring pursues.

I examine these aspects empirically with the case study of the Traffic Light Box Artworks project in Dublin in the following sections.

\section{The Traffic Light Box Artworks project as relocation of innovation}

\section{Dublin City Council Beta (DCC Beta): background and narratives}

The project started as a trial pursued by DCC Beta, which is an experimental initiative led by City Architects, a division of the city council responsible for architectural and urban design. Among various projects that have been pursued by DCC Beta, the 'Traffic Light Box Artworks' seeks to transform city street-scape by giving ordinary, mundane traffic light boxes a paint-over and reflect the neighbourhood in the artworks. In the process of developing the project, DCC Beta collaborated with Code for Ireland to prototype an interactive platform that showcases the artworks and encourages interests and participation in the project.

There are resemblances between the Traffic Light Box Artworks project and the discourses in support of smart city innovations and technocratic governance (Wiig, 2015). Considering traffic light boxes as part of urban infrastructure, the rationale behind the project strikes a chord with the narratives for deploying smarter urban infrastructure. In Hewlett-Packard's white paper on smart 
cities for example, smart infrastructure ‘takes a city’s cultural, socioeconomic, environmental, and geographical realities into account and requires collaboration between stakeholders-from policy makers to citizens', as well as enjoying an extended 'life span' and reducing 'maintenance costs' (HP, 2016: 3-10). In a similar tone, traffic light boxes were an issue for DCC because they 'tend to attract graffiti and stickers, etc - and end up looking very ugly. The Council repaints them regularly (frequency depending on the abuse they're receiving obviously), which creates a cost for the Council' to re-paint them (DCC Beta, 2012). Addressing these issues, the project outlines economic, social, cultural and aesthetic potentials for the city government, communities and local artists through repainting the boxes, which are listed on the webpage of project description:

Save the Council money.

Enhance the area around...making it more attractive.

Strengthen the identity of the area in the minds of the people that live, work, visit and pass through.

Provide an outlet for artists to exhibit their work. (DCC Beta, 2012)

However, DCC Beta’s narrative above already differs from corporate ideals by turning away from focusing on technological driven innovations and to an exploration for the 'relocation' of innovation (Suchman, 2011). DCC Beta seeks to incorporate local and cultural diversities of a city into a trial and placing the trial in Dublin streets is a critical process of infrastructure regeneration. An inspiration for DCC Beta is shown in Figure $1,{ }^{2}$ which is adopted to highlight the importance of fostering local identity in different parts of Dublin in the trial given the diverse characters in different neighbourhoods. The project has hopes for the artworks to 'reinforce/enhance the IDENTITY of that area of the city. We'd like to stress this brief!' (all emphases original):

Let's make sure that they're of relevance to that location, as then they will have even greater impact. For example, Tarsila's art piece above shows a Viking and it's based on the site of the major Viking Settlement that was at Wood Quay. (DCC Beta, 2012)

2 Details of the traffic light box with Viking painting in the artist’s website, http://www.tarsilakruse.com/vikingpainting-at-christ-church/[accessed 8 July 2016]. 

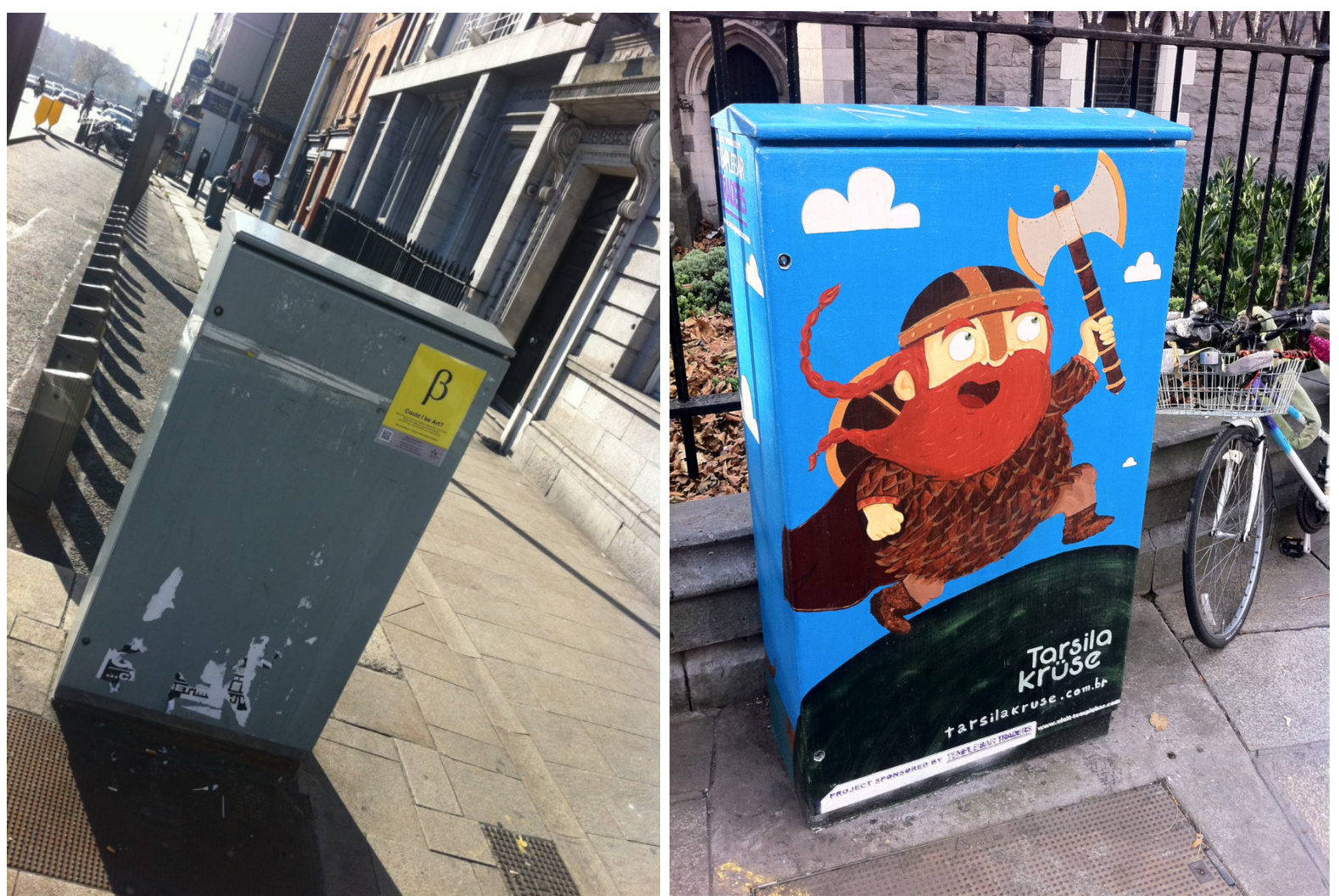

Figure 1: Traffic Light Boxes before with DCC Beta logo (left) and after (right) artworks (source: https://dubcitybeta.wordpress.com/2012/01/19/traffic-light-box-artworks/)

\section{Beta in practice}

Furthermore, DCC Beta is committed to the idea and practices of 'urban hacking', which has a greater emphasis on 'trial-and-error' and treats its trials as 'a new approach to city-making by encouraging, supporting and facilitating experimentation and innovation to improve (public) spaces' (PIVOT Dublin, 2013). This approach is enhanced by forming a partnership with Code for Ireland to develop a prototype of an interactive platform with multiple functionalities: facilitating artworks selection before the boxes are painted; showcasing the painted traffic light boxes online; encouraging interactions with the painted boxes in street via barcodes; and linking back to the details of the artists and their other work via the barcodes or the platform for motivating wider participation.

In November 2014, DCC Beta coordinator attended the monthly meetup of Code for Ireland where he introduced the motivation and aims of the Traffic Light Box Artworks project to the participants and looked for volunteers to work on the project. At this point, the project had already had a previous round of consultation and trial. The project organised an open workshop and invited members of the public to discuss their ideas about the project. Subsequently, 11 traffic light boxes 
were painted and a review of the trial was released afterwards (for more details about the initial stage of the project, see DCC Beta, 2014). At the meetup, the discussion focused on the incorporation of the experiences and results from the initial stage into the next stage of a comparatively larger scale, consisting of up to 20 traffic light boxes and other functionalities of the interactive platform to be added. Through this collaboration, a prototype was built, and the responsibility of maintaining the prototype and the project is taken up by a community group as a community arts project.

Subsequently, in 2015, 41 traffic light boxes were painted, and more to be painted in the summer of 2016. Their locations of the boxes can now be found by accessing an interactive map that also shows the title of the artwork, the artist and other available (or already allocated) boxes (http://dublincanvas.com/map/). The boxes are painted by both professional and non-professional artists, and by and large are related to local characters, characteristics or stories associated with the areas or Dublin more generally.

\section{Co-creating values and uncertainties in collaborative urban infrastructuring}

In the relocation of innovation and experiments into urban everyday life, the Traffic Light Boxes Artworks project also demonstrates many issues emerging from the contradictory spatio-temporal scales and scaling when conducting the project. By examining these issues, this section details the ways in which techno-politics is a product of engaging in the negotiation of values, trust, responsibility, socio-technical imaginary and urban future in collaborative urban infrastructuring.

\section{Temporalities of change and infrastructuring trust}

\section{Unpacking urban temporalities of change}

From very early on, temporalities of change, which are constitutive of but often mutually contradictory in urban everyday life, have been central concerns that motivate collaborative urban infrastructuring. Adding to the temporalities that have already been discussed in participatory design, e.g. 'use time’, 'project time’ and 'infrastructuring time’ (Karasti et al., 2010), the interview with DCC Beta coordinator demonstrates interweaving spatio-temporal commitments, obligations and frustrations: the frustration with the long time a local government can take for any small change, the desire for better 'quality time' with family in the urban environment and thus a strong 
motivation to mobilise a shorter temporal scale of inducing change in the city. The coordinator points out that change in street-scape in Dublin does happen, but the change required decades to occur. The frustration with slow paces of change is shared but others working in DCC and motivates them to establish a loose network of staff across various DCC sections to experiment ways to 'speed up' change:

I was recently at a conference and ... it showed a picture of Grafton Street 40 years ago and said, look how far we have come? Yes absolutely it has changed, but that was 40 years ago as well. ... [I]f I have a kid, if I want to raise them in the city centre, like 10 years is an entire childhood, so you need to be able to, as a city, ... move fast. ... So instead of thinking in terms of decades, how can we think in terms of months? I don't have an exact time, but just get faster. So each time you may be a bit faster than the time before and you learn something new.

Speeding up is also a learning process, as the excerpt above demonstrates, and therefore it becomes a critical issue to maintain or regain, rather than assuming, trust from people (Felt and Fochler, 2008) when introducing trials into Dublin streets. In doing so, however, DCC Beta disrupts established rhythm and expectations of urban regeneration. Several temporal scales and the expectations associated with them, which might not be compatible with one another, can be found rubbing, if not contesting, against one another: their own motivations of speeding up change, people's encouragement expressed in person or online in support of the experiment, their expectations that there is still planning behind an experiment with government backing.

\section{Infrastructuring trust as first step}

Accordingly, collaborative urban infrastructuring requires an infrastructure of trust to conduct trials. The branding of 'beta' is one part of the assemblage of things for DCC Beta to set up the infrastructure (c.f. Asdal and Hobæk, 2016). The term 'beta' is adopted in this context to denote that the experiment conducted by DCC Beta is imperfect and to learn from its deployment is crucial aspect of the experiment, as the coordinator explained in the interview:

So that is why I wanted to develop a brand, I wanted to create a brand in its own right so that when people see it they can implicitly trust it, they know it is going to follow a certain set procedure. It will have a certain ethos and all of that. So that is why I wanted a specific name as opposed to trial or prototype or pilot. 
DCC Beta employs other methods to earn trust in a bottom-up manner. For example, during the time a Beta project is tested, a DCC Beta logo will be displayed at the site of experiments (see left picture in Figure 1) so that people know the project is not a one-off event but is part of an ongoing, experimental governmental initiative. Also, DCC Beta's website explains its motivation, its ethos, the procedures before a Beta project is rolled out and the steps already taken related to specific projects, as well as providing a 'report card' once a project is completed to learn about costs, benefits and lessons from the trials. Accordingly, the logo, documentation, reports and website become the critical 'infrastructure in relation to organized practices' (Star and Ruhleder, 1996: 113) for earning trust while disrupting establish rhythms, norms and expectations for speeding up urban regeneration.

\section{Entangling 'values': for whom and how?}

In the situation where dominant views of value can be resisted and reinterpreted, and regulated and re-enacted in alternative legal, social, technical and ethical terms, the processes of achieving it can produce concerns regarding who benefits and how (Kelty, 2008; Marres, 2012). Similarly, there are aesthetic, cultural, ethical, economic and social values that DCC Beta and its collaboration with Code for Ireland pursue. However, the collaboration to prototype a platform reveals entangled meanings and practices around values, which has consequential effects on how the civic potentials associated with collaborative urban infrastructuring can be pursued and materialised.

\section{Procurement and civic hacking}

'Values' is certainly recognisable in monetary terms and can be contextualised in the wider political economy of civic hacking (Bates, 2012; Gregg, 2015). This way of articulating and enacting values is also observable in collaborative urban infrastructuring. From the perspective of a city council as an established governmental organisation, there are several options for purchasing new digital content or technology from outside of the council. For example, an option for DCC Beta was undertaking established procurement processes to partner with universities or industries for building the platform. Following established procurement procedure avoids risks and uncertainties. A collaboration with a civic hacking organisation as a purchasing model can be risky because it enters uncharted territory. More concerning, such a model can lead to wider societal concerns in relation to government policies and practices in austerity, such as exploiting wilful and free labour and neoliberalising the government. 
However, like issues, values are entangled and 'jointly and antagonistically implicated' in the pragmatic associations that might not be fully reducible to one another (Marres, 2007: 733 original emphasis). If the concerns over exploitation and the neoliberalisation of the government have already created a messy field that collaborative urban infrastructuring has to negotiate, there are, following Björgvinsson (2010), further complications that are 'acted out' through 'passionate engagement’ involving disparate sensibilities and practices about values as DCC Beta develops. For example, there is a worry that procurement procedures are too 'formal' for a 'trial-and-error' approach that DCC Beta seeks to establish. As the coordinator commented in the interview:

But when it came to a digital prototype, ... do I go out and try to procure it, be it a tender or ... I am sure I could but often it is slightly too formal.

Also, undertaking procurement can lose out the opportunity of growing communities and government agencies together for experimenting a more open and inclusive government, as the coordinator continued:

Equally I think there might be a symbiotic relationship there whereby actually something like Code for Ireland get real projects via the city council but actually help Code for Ireland as a concept itself. They know they are working on a real problem somewhere and they actually see it develop, get implemented or not or whatever.

\section{Symbiotic relationship between civic hacking and municipality}

For the coordinator, a symbiotic relationship has also to be a fair and reciprocal one, and implemented in practical ways. For example, there are costs incurred by painting the boxes and participation in building the prototype of the platform to showcase the artworks. In practice, this means making explicit the contributions of the artists, professional or not, who took part in the project, as well as creating tangible values from their participation. As the coordinator noted in the excerpt below, DCC Beta recognises the efforts of those involved in the project and explores possible 'returns' for their contributions, including artists and civic hackers:

... if people are taking time out of their year to paint a box, they ideally would at least have their box mentioned and you could think of things like treasure hunts with people going around all those boxes. If someone could click on a box they could find out who the person who painted it was, maybe they could follow them on social media or whatever. Or maybe when you see a box you could buy a print of that box straight away, maybe that is a side door income stream. 
Indeed, DCC benefits from such a project by saving the human and financial costs of painting the boxes. But, for the coordinator, DCC's responsibility shifts towards trialling possible social, monetary, technological and ethical arrangements to support collaborative urban infrastructuring. By recognising and creating values associated with the artworks and the prototype, what is also envisioned and trialled is the possibility of establishing a sustainable approach to scale up an experimental project and keep its momentum. The goal is for the interested parties to 'growing it themselves' so that the government does not interfere with how they understand and organise the project, how they interpret their place identity, or how the artworks relate to the identity:

So maybe the third item would be if it was carried out as a Dublin Difference project, if we are paying people their expenses, so that is the third thing we are interested in maybe. So after that ... I think we should remove ourselves, they are the only three things we are interested in so we could just be as little interested as possible and actually get out of the way and let the idea grow and let someone else take it, grow it themselves.

\section{Civic hacking and government responsibility}

The value associated with collaborative urban infrastructuring can be further articulated in the tension of taking or withdrawing from government responsibility. 'Grow it themselves' seems to confirm the criticism that local government can outsource its responsibility to the public through civic hacking (Johnson and Robinson, 2014). But growing a symbiotic relationship also requires work and configuring a transitional role for a local council to play. Most significantly, there is a shifting emphasis away from the stewardship of the government and onto exploring 'not only antagonisms between interests or concerns, but also antagonisms between the material, physical and technical associations that come together' (Marres, 2007: 733). This transition of responsibility is observable in the interview excerpt below:

... I mean what are we interested in as a city council? We are interested in maybe picking which boxes get painted and which don't. Maybe the refresh rate, that they are always of a certain quality, that the paint isn't getting really old or that the artwork isn't offensive to people or something.

To be sure, there will be other issues emerging as individual experiments go on. They might concern, for example, the ownership over the decisions about rates, qualities or offensiveness of the painted artworks, which has important consequences regarding whose views and life are legitimised during public experimentation. But this also reminds the idea of 'beta' as something imperfect and 
still growing, by learning from the practical arrangement of trials and the (unexpected) practices developing because of or around them. The 'value' of growing a symbiotic relationship then becomes less concerned with determining and attributing values by adopting existing social or ethical frames. Instead, its rests on the articulation and enactment of practices and viewpoints associated with individual experiments and the reassembling of institutional, technological, spatiotemporal, monetary or ethical arrangements for continual collaborative urban infrastructuring.

\section{Co-creating futures and uncertainties}

For people and the city to sustain collaborative urban infrastructuring and 'grow it themselves', various scaling has to occur: more people and artists to participate, more traffic light boxes to paint and the ownership of the project transferred to individuals or organisations other than DCC Beta. This desirable future also creates uncertainties concerning necessary skills, expertise and knowledge that collaborating government units have to acquire.

\section{Scaling of skills and the multiplicity of municipality}

The issue regarding appropriate ways of procurement surfaces again. In earlier experiments, some other DCC staff tried and found it difficult to follow procurement procedures for rolling out calls for tenders in a way similar to commissioning art pieces by city council. Although the staff had obtained permission from other relevant departments, other problems emerged as the coordinator reflected:

So then the next stage is ok, so now we have all the permissions, how do we actually implement it? So we trialled it two slightly different ways, one was internally, our own staff in the area offices trying to roll it out themselves. And I think they actually found that quite difficult because how did they put the call out? Are they supposed to create their own sub-section on their own website? Are they supposed to...? It was quite a specific set of skills required for it, it was difficult to... They already had their everyday jobs and suddenly they had this extra piece of work to do.

The difficulty of implementing the calls should not be attributed to staff incompetency. Instead, it demonstrates any government's multiplicity (Law and Singleton, 2014), Government agencies are tasked differently and thus develop and possess disparate sets skills and expertise, which strengthens their proficiency at routine tasks but not ad hoc ones that arise as urban experimentation unfolds. The question regarding whether to create more sub-sections or incorporate news tasks to existing workload is also one that hesitates between scaling organisations (by creating more sub- 
sections in the city council) or staff (by requesting upskilling). This difficulty in organisational change to incorporate urban experimentation is an added layer of challenge to existing ones, such as organisational silos or 'multiple overlapping visions and forces that continually jostle with one another, sometimes aligning, other times competing' (Kitchin et al., 2016: 99).

\section{Spatial scaling and diversifying infrastructural objects}

Furthermore, from early on of the project, traffic light boxes are perceived as a pioneering object among many others that can be repurposed. For example, walls have always been on the list and only a small number of them in the inner city had been re-painted. This trial was not on the same scale as the traffic light boxes and did not have a dedicated platform to showcase the repainted walls. However, whether experimenting with the walls or other things, the trials would lead to different considerations and implementation when scaling. Scaling in terms of expanded areas and the number of artworks, as did in the Traffic Light Box Artworks project, has its own difficulty already. But as the DCC Beta coordinator also commented, when scaling has the intention to include a different set of things in the infrastructural network, it would incur changes to other parts in the infrastructure, leading to further social, governmental, legal and administrative issues:

... but there is a whole set of other things that you need to look ... what assets are involved, liability or ownership, who do you sue if something goes wrong and so on. So a whole set of things there that need to be discussed. That is partly still only being figured out a little bit.

\section{Promising futures and future problems}

Collaborative urban infrastructuring generates promising futures and future problems in the scaling of the ethical, material, spatio-temporal and socio-technical arrangements of the trials. The 'situational contingencies' and 'performative effects' that occur during the experiments are a 'practice of doing politics’ (Voß and Amelung, 2016: 763; original emphasis). It can disrupt established orders of organisational norms, skills, expertise and knowledge and lead to uncertain future, however desirable the vision has been. DCC Beta started as an informal network of staff, experimenting new approaches to change the city, and has been adopted as a formal DCC procedure since 2015.

The adoption by DCC brings excitement and further questions. The positive side includes a steadier budget, although small, support from a senior member of council staff and a steering group that 
enrols more sections of the council into DCC Beta. However, as the experimentation grows larger, it remains uncertain as to the legitimate time that could be spent on responding appropriately to the growing requests for trials by the coordinator and other staff who are enthusiastic about joining. Also, when DCC Beta was only a concept in trial, the inclusion and prioritisation of requests can be handled with informally since the numbers of the involved individuals and communities were small. But when DCC Beta is formally adopted by the council, providing transparency concerning how requests are processed and how decisions should made become a demanding and difficult task.

Conflicting spatio-temporal scaling again adds further challenges to articulating the future for the city and DCC Beta. Whether individual trials are to stay in a local community and have the potential for city-wide roll-out, they are designed and tested locally. This has several unexpected effects. People who experience the trials might think the trials are small and limited in scope, whereas DCC Beta as a trial itself aims at providing the whole city an alternative city making mechanism.

Also, trials are conducted, often on the scale of months, to allow review and modification, and therefore the public might neglect that growing DCC Beta is a long-term project, occurring on the scale of years to a decade. Because individual trials are adapted to local contexts, there are complexities and contingencies that are difficult to simplify for reporting DCC Beta's progress or impact to city council's senior management. However, whether making a case for more resources or being accountable for the budget, the report or presentation to senior management has to be short, and delivering a clear, succinct and persuasive examination on the progress or impact can take many extra hours away from normal line of duty and working on the trials. Adding to these uncertainties is that the inclusion of more citizens for more reflexive, deliberative, accountable and democratic urban experimentation is not sufficient. Citizen panels are 'political and not a neutral instruments' because the design of the panel 'is a decision of political process', which is firmly situated in, as demonstrated throughout the paper, '[d]ifferences in worldviews and philosophical orientations' regarding what constitutes as legitimate opinions and concerns (Mann et al., 2014: 40).

\section{Conclusion}

Infrastructure regeneration that addresses citizen and community needs are often promoted as key features in developing smart cities and data-driven urbanism. However, the practices of engaging and further developing such visions are often lacking in larger-scale smart city initiatives and can be 
overshadowed by corporate interests, governance convenience and efficiency, and an overemphasis on technological innovations. Instead of relying on multinational corporations to negotiate partnership with local governments, various civic hacking and government organisations collaborate and experiment transparent and inclusive ways of engineering future cities and addressing local issues.

In this paper, I suggest to analyse such experimentation through the lens of collaborative urban infrastructuring for articulating techno-politics as it emerges from continual, pragmatic and agonistic arrangements for engineering cities in bottom-up and inclusive ways. DCC Beta and the Traffic Light Box Artworks project are examined to detail how they have developed and scaled from a small, experiment initiative into a procedure incorporated by the city council. The analysis demonstrates that the spatio-temporal scaling of a trial to include diverse viewpoints and values is a performative process that leads to the continual scaling of other social, technological and organisational arrangements. These arrangements intend to be complimentary to the societal and ethical values of the trial, but can become implicated by the scaling of government structures or capabilities. The adjustment of government procedures, tasks, knowledge and skills are challenging, and the legitimisation and value of the time on making these adjustments require formal recognition. The spatio-temporal, socio-technical and organisational scaling thus complicate the articulation and enactment of the values that motivate collaborative urban infrastructuring.

Accordingly, the heterogeneous scaling that occurs as collaborative urban infrastructuring unfolds produces desirable futures and future problems. Such scaling can enhance the incorporation of diverse values, viewpoints and practices into the envisioning and engineering of future cities. At the same time, these values and practices are also implicated by the agonistic relationships when exploring practical arrangements.

The analysis of DCC Beta makes explicit critical issues emerging from pursuing more open, transparent and collaborative innovation and urban governance. The formal adoption of DCC Beta by the city council is an encouragement for continual experimentation. But the complexity of decision making and impact evaluation also grows when greater diversity of people, viewpoints, practices and things can become entangled in surprising ways. Accordingly, it becomes important to critically design, experiment and reflect possible practices of taking responsibility that can prevent collaborative urban infrastructuring from assuming patriarchal stewardship and taking an all- 
knowing position of caring and evaluation (Massey, 2004). This calls for not only more trials but also methods to disclose urban techno-politics that emerges continuously and in unanticipated ways.

\section{Acknowledgement}

I would like to thank DCC Beta and Code for Ireland for their generosity and productive conversation along the research journey. I am also thankful for the constructive and encouraging comments from Aoife Delaney, Bob Bradshaw, Caspar Menkman, Claudio Coletta, Jim White and Rob Kitchin, and the engaging discussion with the participants of Creating Smart Cities Workshop at Maynooth University in 2016. The research for this paper was conducted under The Programmable City project, funded by a European Research Council Advanced Investigator award (ERC-2012-AdG-323636-SOFTCITY).

\section{References}

Asdal K and Hobæk B (2016) Assembling the whale: Parliaments in the politics of nature. Science as Culture 25(1): 96-116.

Barry A (2013) Material Politics: Disputes along the Pipeline. Oxford: Wiley Blackwell.

Bates J (2012) 'This is what modern deregulation looks like': Co-optation and contestation in the shaping of the UK’s Open Government Data Initiative. The Journal of Community Informatics 8(2). Available from: http://ci-journal.net/index.php/ciej/article/view/845/916.

Bell D (1973) The Coming of Post-industrial Society: A Venture in Social Forecasting. New York: Basic Books.

Berkhout F (2002) Technological regimes, path dependency and the environment. Global Environmental Change 12(1): 1-4.

Bjögvinsson E, Ehn P and Hillgren P-A (2012) Design things and Design thinking: Contemporary participatory design challenges. Design Issues 28(3): 101-116.

Björgvinsson E, Ehn P and Hillgren P-A (2010) Participatory design and 'democratizing innovation’. In: Proceedings of the 11th Biennial Participatory Design Conference, NY: ACM, pp. 41-50. 
Blomberg J and Karasti H (2013) Reflections on 25 Years of ethnography in CSCW. Computer Supported Cooperative Work (CSCW) 22(4-6): 373-423.

Büscher M, Eriksen MA, Kristensen JF, et al. (2004) Ways of grounding imagination. In: Proceedings of the Eighth Conference on Participatory Design: Artful Integration: Interweaving Media, Materials and Practices, NY: ACM, pp. 193-203.

Castells M (1996) The Rise of Network Society. Oxford: Blackwell.

Castells M (2008) The new public sphere: Global civil society, communication networks, and global governance. The ANNALS of the American Academy of Political and Social Science 616(1): 78-93.

Coleman EG (2013) Coding Freedom: The Ethics and Aesthetics of Hacking. Princeton, NJ: Princeton University Press.

Coleman S (2008) Foundations of digital government. In: Chen H, Brandt L, Gregg V, et al. (eds), Digital Government: E-Government Research, Case Studies, and Implementation, Integrated Series In Information Systems, Boston, MA: Springer, pp. 3-19.

CUSP (2014) NYU CUSP, related Companies, and Oxford Properties Group team up to create 'First Quantified Community’ in the United States at Hudson Yards. NYU Center for Urban Science and Progress. Available from: http://cusp.nyu.edu/press-release/nyu-cusp-relatedcompanies-oxford-properties-group-team-create-first-quantified-community-united-stateshudson-yards/ (accessed 25 October 2016).

Dawes SS (2009) Governance in the digital age: A research and action framework for an uncertain future. Government Information Quarterly, Building the Next-Generation Digital Government Infrastructures 26(2): 257-264.

DCC Beta (2012) Traffic Light Box Artworks - 1 / 11 / 111. Dublin City Council Beta Projects. Available from: https://dubcitybeta.wordpress.com/2012/01/19/traffic-light-box-artworks/ (accessed 8 July 2016).

DCC Beta (2014) Report card: Traffic light box artworks. Dublin: Dublin City Council. Available from: https://dubcitybeta.files.wordpress.com/2014/09/traffic-light-boxes-report-cardpublic.pdf (accessed 12 July 2016). 
Dutil PA, Howard C, Langford J, et al. (2008) Rethinking government-public relationships in a digital world. Journal of Information Technology \& Politics 4(1): 77-90.

Felt U and Fochler M (2008) The bottom-up meanings of the concept of public participation in science and technology. Science and Public Policy 35(7): 489-499.

Gabrys J and Yusoff K (2012) Arts, sciences and climate change: Practices and politics at the threshold. Science as Culture 21(1): 1-24.

Gregg M (2015) Hack for good: Speculative labour, app development and the burden of austerity. The Fibreculture Journal (25): 185-202.

HP (2016) Smart cities and the Internet of Things: Municipal transformation with the HPE Universal IoT Platform. Palo Alto, CA: HP.

Janssen M, Charalabidis Y and Zuiderwijk A (2012) Benefits, adoption barriers and myths of Open Data and Open Government. Information Systems Management 29(4): 258-268.

Johnson P and Robinson P (2014) Civic hackathons: Innovation, procurement, or civic engagement? Review of Policy Research 31(4): 349-357.

Karasti H (2014) Infrastructuring in participatory design. In: Proceedings of the 13th Participatory Design Conference, NY: ACM, pp. 141-150.

Karasti H and Baker KS (2008) Community Design: growing one’s own information infrastructure. Proceedings of the Tenth Anniversary Conference on Participatory Design 2008: 217-220.

Karasti H, Baker KS and Millerand F (2010) Infrastructure time: Long-term matters in collaborative development. Computer Supported Cooperative Work (CSCW) 19(3-4): 377-415.

Kelty C (2008) Two Bits: The Cultural Significance of Free Software. Durham, NC: Duke University Press.

Kitchin R, Maalsen S and McArdle G (2016) The praxis and politics of building urban dashboards. Geoforum 77: 93-101.

Law J and Singleton V (2014) ANT, multiplicity and policy. Critical Policy Studies 8(4): 379-396. 
Le Dantec CA and DiSalvo C (2013) Infrastructuring and the formation of publics in participatory design. Social Studies of Science 43(2): 241-264.

Liegl M, Boden A, Büscher M, et al. (2016) Designing for ethical innovation: A case study on ELSI co-design in emergency. International Journal of Human-Computer Studies 95: 80-95.

Lodato TJ and DiSalvo C (2016) Issue-oriented hackathons as material participation. New Media \& Society 18(4): 539-557.

Maalsen S and Perng S-Y (2016) Encountering the city at hacking events. In: Kitchin R and Perng S-Y (eds), Code and the City, London and NY: Routledge.

Mann C, Voß J-P, Amelung N, et al. (2014) Challenging futures of citizen panels: Critical issues for robust forms of public participation. Berlin: Technische Universität Berlin.

Marres N (2007) The issues deserve more credit: Pragmatist contributions to the study of [ublic involvement in controversy. Social Studies of Science 37(5): 759-780.

Marres N (2012) Material Participation: Technology, the Environment and Everyday Publics. Basingstoke: Palgrave Macmillan.

Massey D (2004) Geographies of Responsibility. Geografiska Annaler: Series B, Human Geography 86(1): 5-18.

Mattern S (2016) Instrumental city: The view from Hudson Yards. Places Journal. Available from: https://placesjournal.org/article/instrumental-city-new-york-hudson-yards/ (accessed 25 October 2016).

Perng S-Y and Kitchin R (2016) Solutions and frictions in civic hacking: Collaboratively designing and predicting wait time for an immigration office. Social \& Cultural Geography. OnlineFirst, doi:10.1080/14649365.2016.1247193.

PIVOT Dublin (2013) Dublin adopts urban hacking as a city-making tool. PIVOT Dublin. Available from: http://www.pivotdublin.com/blog/dublin_adopts_urban_hacking_as_a_city_making_tool/ (accessed 9 July 2016). 
Shelton T, Zook M and Wiig A (2015) The ‘actually existing smart city’. Cambridge Journal of Regions, Economy and Society 8(1): 13-25.

Star SL and Ruhleder K (1996) Steps toward an ecology of infrastructure: Design and access for large information spaces. Information Systems Research 7(1): 111-134.

Suchman L (2011) Anthropological relocations and the limits of design. Annual Review of Anthropology 40(1): 1-18.

Voß J-P and Amelung N (2016) Innovating public participation methods: Technoscientization and reflexive engagement. Social Studies of Science 46(5): 749-772.

Weber M (1964) The theory of social and economic organization. New York: The Free Press.

Wiig A (2015) IBM’s smart city as techno-utopian policy mobility. City 19(2-3): 258-273. 